\title{
ANÁLISE DA ACCOUNTABILITY NO INSTITUTO DE PREVIDÊNCIA MUNICIPAL DOS SERVIDORES PÚBLICOS DO MUNICÍPIO DE VIÇOSA/ MG (IPREVI)
}

\author{
Accountability Analysis in the Public Servants Social Security Institute Ofviçosa-Mg (Iprevi)
}

Análisis de la Accountabilidad en el Instituto de Previsión Municipal de los Servidores Públicos del Municipio de Viçosa / Mg (Iprevi)

Fabrícia Júnia de Oliveira Martins Mestrado em Administração (Concentração em Administração Pública) pela Universidade Federal de Viçosa Advogada

http://lattes.cnpq.br/7980290030399342 https://orcid.org/0000-0002-8573-2280

fabricia.martins@ufv.br

Thiago de Melo Teixeira da Costa Doutorado em Economia Aplicada pela Universidade Federal de Viçosa Professor Associado do Departamento de Administração e Contabilidade http://lattes.cnpq.br/3856349103878126 https://orcid.org/0000-0002-0521-3799 thiagocosta@ufv.br

Bruno Tavares

Doutorado em Administração pela Universidade Federal de Lavras Professor Adjunto do Departamento de Administração e Contabilidade http://buscatextual.cnpq.br/buscatextual/visualizacv.do?id=K4777504Y2 https://orcid.org/0000-0002-5140-7359

btavares@ufv.br

Wagner Belchior Dias Doutorando em Ciências Contábeis pela Universidade Federal do Rio de Janeiro Estudante de Doutorado http://lattes.cnpq.br/0088510335628261 https://orcid.org/0000-0001-5181-8038 wbelchior@facc.ufrj.br

Resumo: Este artigo apresenta o cenário da accountability no Instituto de Previdência dos Servidores Públicos do Município de Viçosa/MG - IPREVI. Assim, o escopo desse estudo de caso foi investigar se os mecanismos institucionalizados de accountability vertical, horizontal e social estão presentes na referida unidade gestora. A análise foi realizada por meio do Instrumento de Identificação e Avaliação do processo de Accountability nas Unidades Gestoras do Regime Próprio de Previdência Social - RPPS - municipal que agrupa dois inventários desenvolvidos por Martins (2015): o Inventário normativo da accountability aplicada ao RPPS (INA) e o Inventário de perfil e percepção do segurado sobre o processo de accountability (IPPSA). Observou-se que há no IPREVI mecanismos institucionalizados capazes de viabilizar a realização da accountability nessas três classificações. Entretanto, os resultados indicaram que 0 elemento Informação Transparente é o mais precário em todas as análises realizadas, inclusive no aspecto institucional, o que compromete também a realização dos demais elementos, sobretudo, a participação e interação do segurado.

Palavras-chave: Accountability; Previdência; Unidade Gestora do RPPS; IPREVI.

\begin{abstract}
This article presents the accountability scenario from the Public Servants Social Security Institute of Viçosa/-MG - IPREVI. Thus, the scope of this study was to investigate if the vertical, horizontal and social accountability institutionalized mechanisms are present in the aforementioned management unit. The analysis was carried out using the Instrument of Identification and Evaluation of the Accountability process at the Management Units of the municipal RPPS. This instrument combines two inventories developed by Martins (2015): the Normative Inventory of Accountability (INA) applied to RPPS and the Inventory of the Insured's Profile and Perception about the process of Accountability process (IPPSA). It was observed that in this institution, there are institutionalized mechanisms capable of making accountability possible in these three classifications. However, the results indicated that the element of Transparent Information is the most precarious in all the analyzes conducted, including under the institutional aspect, which also compromises the realization of the other elements, above all, the participation and interaction of the insured.
\end{abstract}

Keywords: Accountability; Social Security; RPPS Management Unit; IPREVI.
Resumen: Este artículo presenta el escenario de la accountability en el Instituto de Previsión de los Servidores Públicos del Municipio de Viçosa/MG - IPREVI. Así, el objetivo de este estudio de caso fue investigar si los mecanismos institucionalizados de accountability vertical, horizontal y social están presentes en la referida unidad gestora. El análisis fue hecho a través del Instrumento de Identificación y Evaluación del proceso de accountability en las Unidades Gestoras del RPPS municipal que agrupa dos inventarios desarrollados por Martins (2015): el Inventario normativo de la accountability aplicada al RPPS(INA) y el Inventario de perfil y percepción del asegurado sobre el proceso de accountability (IPPSA).Se observó que en el IPREVI haymecanismos institucionalizados capaces de viabilizar la realización de la accountability en esas las tres clasificaciones mencionadas. No obstante, los resultados indicaron que el elemento Información transparente es el más precario en todos las análisis realizados, incluso en el aspecto institucional, lo que compromete también la realización de los demás elementos, sobre todo, la Participación e interacción del asegurado.

Palabras clave: Accountability; Previsión Unidad Gestora del RPPS; IPREVI.

Texto completo em português: http://www.apgs.ufv.br Full text in Portuguese: http://www.apgs.ufv.br

\section{Introdução}

A realidade institucional dos Regimes Próprios de Previdência Social (RPPS), no Brasil, possui todo um aparato normativo que deveria potencializar a realização da accountability nas respectivas unidades gestoras. Essa circunstância pode ser observada pela exigência legal de: práticas que promovam a cultura da transparência ativa nos órgãos e entidades da Administração direta e indireta; participação e envolvimento do segurado na gestão do regime através dos Conselhos Gestores e audiências públicas; existência de mecanismos rígidos e agentes específicos de controle; e, também, a previsão de sanções punitivas como consequência da gestão irregular dos recursos previdenciários. 
Entretanto, embora todos RPPS possuam como pilar essas circunstâncias institucionais que podem desencadear no processo constante de avaliação e responsabilização que representa a accountability, fato é que, na prática, a realização dessas exigências normativas encontra empecilhos devido à realidade organizacional de cada unidade gestora. Desse modo, a descentralização desses regimes em cada ente da federação, quando existente, faz com que a estrutura micro de cada RPPS seja diferenciada, como consequência, a realização da accountability também.

Ressalta-se, todavia, que além das circunstâncias concretas de cada RPPS influenciarem na análise da accountability, esta se estabelece por meio de várias relações a partir das quais poderá ser examinada de maneira vertical ou horizontal, como a classifica O'Donnell (1998); e/ou social, conforme ensinam Peruzzotti and Smulovitz (2000).

Assim, quando observada como processo de avaliação e responsabilização que ocorre entre a sociedade e o Estado, haverá uma relação de accountability vertical, e, nesse sentido, o instrumento por meio do qual se materializa é a eleição. No plano horizontal, a accountability é realizada por órgãos e agentes do próprio Estado dotados de poderes de fiscalização. Já a social, também conhecida como vertical não eleitoral (Robl Filho, 2013), acontece na relação que se estabelece entre o Estado e a sociedade por meio de diversos mecanismos, institucionalizados ou não, como os espaços de participação, através da mídia e/ou mesmo de movimentos sociais.

Essa conjuntura é que justifica a necessidade de uma análise pontual da accountability em cada RPPS e sua respectiva unidade gestora, já que as potencialidades de concretização desse processo de avaliação e responsabilização podem variar a depender do contexto. Por esse motivo, este estudo tem como pilar o seguinte questionamento: qual é o cenário da accountability no Instituto de Previdência Municipal dos Servidores Públicos (IPREVI) do Município de Viçosa/ MG?

Assim, o objetivo desse estudo de caso é investigar se os mecanismos institucionalizados de accountability vertical, horizontal e social estão presentes no IPREVI.

Essa unidade gestora foi escolhida como objeto de análise devido à acessibilidade aos dados e, sobretudo, à adequação às exigências normativas gerais de constituição e funcionamento do RPPS, conforme prevê a Lei Geral da Previdência (Lei n. 9.717, de 27 de novembro de 1998).

\section{Fundamento teórico: conceito, elementos e classificações da accountability}

Accountability é conceituada como "a avaliação e responsabilização permanente dos gestores públicos em razão dos atos praticados em decorrência do uso do poder que lhes é outorgado pela sociedade" (Rocha, 2011, p. 86). Para a realização desse processo, a literatura indica a existência de mecanismos de vigilância e restrições institucionais em relação ao exercício desse poder, cujos principais elementos citados são informação, justificação e sanção (Schedler, 1999; Rocha, 2013; Robl Filho, 2013).

No entanto, ao compreender a accountability vinculada a essa finalidade, que é o controle do poder em sentido amplo, imprescindível, além desses elementos, um conjunto mais extenso de estruturas e condições interdependentes para a realização desse controle. Esse é o motivo pelo qual são considerados elementos fundamentais para compreensão da accountability: a informação transparente sobre os atos (que compreende a justificação e também a prestação de contas em seu sentido formal e material); a possibilidade de envolvimento e participação daqueles que delegam o poder; a existência de mecanismos institucionalizados de controles internos e externos; e, por fim, a previsão de sanções que possibilitem a sua aplicação (Martins, 2015).

Esse processo que desencadeia a avaliação e responsabilização do gestor público é classificado a partir da ótica das relações entre quem exerce o poder e quem o avalia. Assim, para O'Donnell (1998), a accountability pode ser classificada como vertical e horizontal. Vale dizer, vertical quando ocorre por meio do processo eleitoral e horizontal quando estabelecida como sistema de controle entre os poderes, no qual os agentes do próprio Estado realizam a avaliação e aplicam as sanções decorrentes.

Não obstante, em virtude da multiplicação de atores sociais e da limitação democrática fundada apenas na representação, outra classificação foi cunhada por Peruzzotti and Smulovitz (2000): a accountability societal. Esta é compreendida como a que é "exercida diretamente pela sociedade sobre os agentes públicos, eleitos, nomeados ou permanentes” (Rocha, 2011, p.87).

\section{Procedimentos Metodológicos}

O estudo foi realizado no município de Viçosa, localizado na Zona da Mata do estado de Minas Gerais, cuja estratégia de investigação foi o método de estudo de caso (Yin, 2001) da accountability na unidade gestora do RPPS dos servidores deste Município - o IPREVI.

Para essa investigação, foi realizada pesquisa de natureza descritiva e exploratória com abordagem quantitativa e qualitativa. Os meios de pesquisa utilizados foram: a pesquisa documental, bibliográfica e de campo. Quanto à pesquisa de campo, esta ocorreu por meio de entrevistas aplicadas aos segurados do IPREVI e de incursões exploratórias realizadas na sede desse instituto durante o ano de 2014, ocasiões nas quais foram debatidas em reuniões esclarecimentos sobre as funções da unidade gestora atinentes ao exame da accountability e o cotidiano da gestão em relação às exigências institucionais.

Assim, a coleta dos dados foi pautada no Instrumento de Identificação e Avaliação do processo de Accountability nas Unidades Gestoras do RPPS municipal, que agrupa dois inventários desenvolvidos por Martins (2015): o Inventário normativo da accountability aplicada ao RPPS (INA) e o Inventário de perfil e percepção do segurado sobre o processo de accountability (IPPSA). 
Desse modo, para o desenvolvimento da fase descritiva das condições institucionais da accountability no IPREVI utilizou-se, por meio dos documentos disponibilizados na rede mundial de computadores sobre a referida unidade gestora, em sítio próprio e no dos órgãos de controle, o INA como parâmetro para identificação e posterior análise desse panorama institucional.

Quanto à fase exploratória, essa foi concretizada por meio das entrevistas estruturadas constantes no IPPSA, elaboradas em formato de questionário com a predominância de questões em escala tipo Likert de 5 pontos, variando de 1 (discordo totalmente) até 5 (concordo totalmente).

Nessa segunda etapa da investigação, participaram como sujeitos da pesquisa servidores públicos ocupantes de cargo efetivo em atividade que são segurados do IPREVI. Devido à extensão do instrumento de análise, optou-se por aplicá-lo a uma amostra representativa extraída da população dos 1.180 (um mil cento e oitenta) servidores ocupantes de cargo efetivo do município, cujo cálculo foi baseado em uma confiabilidade de 95\%. Assim, a amostra desse estudo englobou 90 (noventa) sujeitos de pesquisa.

A amostragem foi composta por homens (48,9\%) e mulheres $(51,1 \%)$ com faixa etária variada, sendo a maioria (58\%) entre 36 a 50 anos. O nível de escolaridade entre os segurados entrevistados também variou entre os que cursaram até o ensino fundamental (20\%), o ensino médio (39\%), cursos técnicos (3\%) e os possuem formação em curso de nível superior (38\%).

Esses dados foram coletados por meio da pesquisa de campo nos órgãos e entidades do município de Viçosa/MG durante os meses de dezembro de 2014 e janeiro de 2015, por meio de amostragem não probabilística, determinada por conveniência, cujo critério de escolha foi a acessibilidade do servidor em participar da pesquisa.

Posteriormente, foi realizado o exame de confiabilidade dos constructos que compõe a accountability pelo coeficiente alfa de Cronbach. Nessa análise, utilizou-se como referência a média do comportamento da variabilidade conjunta dos itens considerados, cujos parâmetros variam de " 0 a 1, sendo os valores de 0,60 a 0,70 considerados o limite inferior de aceitabilidade" (Hair, Black, Babin, Anderson \& Tathan, 2009, p. 100).

Em seguida, os dados obtidos pelo IPPSA foram submetidos à análise estatística descritiva e exploratória (AED) para a investigação do comportamento dos dados em cada constructo e das suas características importantes.

Nas questões de escala nominal, cujo padrão de resposta foi 'não sei', 'não' e 'sim', o foco da análise foi nos valores apresentados pela moda, medida de tendência central que descreve o escore mais comum em qualquer distribuição (Levin, Fox \& Ford, 2012). Todos esses procedimentos estatísticos foram processados no programa estatístico SPSS®.

Dessa forma, por meio dos quesitos do INA foram observados os seguintes critérios do modelo de análise da accountability no IPREVI: a) Informação transparente: canais de informação e transparência ativa; b) Participação e envolvimento do Segurado: estímulo à participação; c) Mecanismos de controle: espécies de controle e, em partes, a qualidade (nos aspectos formais); d) Sanções: espécies e natureza das sanções existentes.

O IPPSA, além de auxiliar no exame desses critérios, também permitiu a análise dos demais, ou seja: a) Informação transparente: transparência passiva, qualidade da informação, motivação e justificação; b) Participação e envolvimento do Segurado: interesse do segurado e qualidade da participação. c) Mecanismos de controle: qualidade do controle (na percepção do segurado); d) Sanções: eficácia (na percepção do segurado).

\section{Resultados e Discussões \\ 4.1. Panorama institucional da accountability no IPREVI}

No município de Viçosa/MG, o RPPS foi instituído em 2002 pela Lei Complementar municipal n. ${ }^{\circ} 1.511$, de 19 de novembro de 2002. Ao estabelecer as normas que regulamentam a proteção previdenciária dos seus servidores, essa lei também criou a unidade gestora do regime: o Instituto de Previdência Municipal dos Servidores do Município de Viçosa/MG (IPREVI).

O IPREVI foi instituído como entidade autárquica de previdência municipal com a atribuição específica de operar e administrar os planos de benefícios e de custeio da previdência desses servidores. Em sua estrutura organizacional, há um Conselho Municipal de Previdência, Conselho Fiscal, Comitê de Investimentos, Diretoria Executiva, Diretoria Geral, Diretoria Previdenciária e Diretoria Administrativo-Financeira, além da Chefia de Contabilidade e Recursos Humanos e assistentes administrativos.

O RPPS desse município tem caráter contributivo. Isso significa que o ente público, os segurados (ativos e inativos) e pensionistas contribuem para a formação do fundo de previdência, conforme limites de alíquotas estabelecidos em lei. Além disso, todos os benefícios ofertados pelo RPPS possuem fonte de custeio correspondente.

Portanto, o IPREVI cumpre as exigências normativas mínimas referentes à estrutura e funcionamento do RPPS.

No Quadro 01, estão descritos, de forma sucinta, os elementos de accountability analisados no instituto em questão. 


\begin{tabular}{|c|l|}
\multicolumn{2}{|c}{ Quadro 01 -Resumo do panorama institucional da accountability no IPREVI } \\
\hline \multicolumn{2}{|c|}{ RESUMO DO PANORAMA INSTITUCIONAL DA ACCOUNTABILITY NO IPREVI } \\
\hline Estrutura mínima & O IPREVI cumpre as exigências normativas mínimas referentes à estrutura e funcionamento do RPPS. \\
\hline $\begin{array}{c}\text { Informação } \\
\text { transparente }\end{array}$ & $\begin{array}{l}\text { A estrutura do IPREVI e algumas práticas desta organização sugerem uma política de transparência ativa ainda rudimentar, mas com } \\
\text { potencial para se desenvolver. }\end{array}$ \\
\hline $\begin{array}{c}\text { Participação e } \\
\text { interação }\end{array}$ & $\begin{array}{l}\text { Institucionalmente o IPREVI possui colegiado com a participação paritária de representantes dos poderes e dos servidores, ativos e } \\
\text { inativos, que acompanha e fiscaliza a gestão do regime. } \\
\text { Quanto à realização de audiências públicas, estas são promovidas pelo Poder Legislativo municipal e abordam apenas os aspectos } \\
\text { patrimoniais da gestão do IPREVI. }\end{array}$ \\
\hline $\begin{array}{c}\text { Mecanismos de } \\
\text { Controle }\end{array}$ & $\begin{array}{l}\text { O IPREVI se submete formalmente ao controle dos vários órgãos com atribuições específicas para esse fim e por meio dos inúmeros } \\
\text { instrumentos institucionalizados pela legislação. }\end{array}$ \\
\hline Sanção & $\begin{array}{l}\text { Foram observadas sanções positivas, a exemplo da concessão de parcelamento de débitos do ente federativo com o IPREVI e a } \\
\text { emissão do Certificado de Regularidade Previdenciária (CRP). } \\
\text { Quanto às sanções negativas (punitivas), há indícios de que não há fato que enseja a aplicação das sanções no período estudado. }\end{array}$ \\
\hline
\end{tabular}

Fonte: Resultados da pesquisa.

Numericamente este panorama institucional pode ser expresso conforme demonstram os percentuais de observância de cada elemento da accountability listados na Tabela 1.

Tabela 1 Percentual dos quesitos contemplados pelo IPREVI no INA

\begin{tabular}{|c|c|c|c|}
\hline \multicolumn{4}{|c|}{ QUESITOS DO INVENTÁRIO NORMATIVO } \\
\hline Dimensão & Investigados & Contemplados & Percentual \\
\hline Participação e Interação & 4 & 3 & $75,00 \%$ \\
\hline Sanções ${ }^{a b}$ & 10 & 0 & $0,00 \%$ \\
\hline Total & 154 & 127 & $82,47 \%$ \\
\hline
\end{tabular}

Nota. Fonte: Resultados da Pesquisa

a Análise com base na regularidade do IPREVI junto aos órgãos de controle. ${ }^{b}$ Não foram encontrados registros de sanções punitivas.

Diante do exposto, constata-se que formalmente, no plano normativo, o IPREV observa os aspectos institucionais que potencializam a accountabilty no plano concreto. No entanto, os elementos "Informação Transparente" e "Participação e Interação" são os que necessitam, respectivamente, de maiores aperfeiçoamentos para atenderem integralmente os quesitos do INA.

\subsection{Percepção dos segurados do IPREVI sobre accountability}

Foram entrevistados segurados de ambos os sexos, em faixas etárias e níveis de escolaridade diversificados. Além disso, as entrevistas foram realizadas com servidores lotados em variados órgãos e entidades do município, cujos cargos e funções também são diversificados.

Destarte percebe-se que a amostra apresentou-se muito heterogênea e, por isso, capaz de permitir análise da população de segurados ativos do IPREVI, seu perfil e suas percepções.

\subsubsection{Informação Transparente}

O elemento Informação Transparente que compõe a accountability refere-se ao ato de divulgar informações de maneira transparente, justificando as decisões e prestando conta dos atos de forma confiável e inteligível, dentro de um prazo razoável.

\section{A. Perfil do segurado sobre Informação Transparente}

As variáveis elaboradas para representar o perfil do segurado sobre o elemento Informação Transparente foram estruturadas em dois grupos: o das variáveis nominais (Tabela 2) e o das variáveis em escala de concordância (Tabela 3).

No que tange às variáveis nominais, os resultados indicaram que o segurado compreende o caráter contributivo da previdência no que se refere a sua contribuição e ao valor aproximado que é retido para esse fim. Todavia, não sabe que o município também tem a obrigação de contribuir para formação do fundo e desconhece o valor desta contribuição.

Tabela 2- Frequências do constructo Perfil sobre Informação Transparente.

\begin{tabular}{|c|c|c|c|c|}
\hline \multicolumn{2}{|c|}{ PERFIL INFORMAÇÃO TRANSPARENTE } & NÂO SEI & NÃO & SIM \\
\hline \multirow{5}{*}{$\begin{array}{l}\text { Contribuem mensalmente } \\
\text { para a sua Previdência: }\end{array}$} & você próprio, como servidor. & $1,1 \%$ & $4,4 \%$ & $94,4 \%$ \\
\hline & a prefeitura (poder público municipal) & $45,6 \%$ & $16,7 \%$ & $37,8 \%$ \\
\hline & o IPREVI (Instituto de Previdência do Município de Viçosa/MG) & $44,4 \%$ & $22,2 \%$ & $33,3 \%$ \\
\hline & o governo federal & $43,3 \%$ & $55,6 \%$ & $1,1 \%$ \\
\hline & Outro & $38,9 \%$ & $55,6 \%$ & $5,6 \%$ \\
\hline \multirow{2}{*}{$\begin{array}{c}\text { Conhece aproximadamente o } \\
\text { valor da contribuição } \\
\text { previdenciária realizada: }\end{array}$} & por você, enquanto servidor & $1,1 \%$ & $6,7 \%$ & $92,2 \%$ \\
\hline & pela prefeitura (poder público municipal) & $2,2 \%$ & $77,8 \%$ & $20,0 \%$ \\
\hline
\end{tabular}

Nota. Fonte: Resultados da pesquisa. 
Nessa análise do conhecimento sobre alguns aspectos da previdência, os resultados indicaram que os segurados sabem o que é previdência e também finalidade do IPREVI. Porém, o valor da média indica que esses não compreendem bem o que é o Regime Próprio de Previdência (Tabela 3).

Tabela 3 - Valores estatísticos das variáveis de escala que compõe o constructo Perfil sobre Informação Transparente

\begin{tabular}{|c|c|c|c|}
\hline PERFIL INFORMAÇÃO TRANSPARENTE & MODA & MÉDIA & $\begin{array}{l}\text { DESVIO } \\
\text { PADRÃOO }\end{array}$ \\
\hline Compreendo o que é Previdência. & 4 & 4,26 & 4,323 \\
\hline Compreendo o que é Regime Próprio de Previdência Social (RPPS). & 4 & 3,30 & 1,487 \\
\hline Compreendo o que é o IPREVI (Instituto de Previdência do Município de Viçosa/MG). & 5 & 4,12 & 1,090 \\
\hline Conheço a finalidade do IPREVI. & 5 & 4,07 & 1,188 \\
\hline Tenho interesse nas informações sobre Previdência e/ou o IPREVI. & 5 & 4,39 & 1,057 \\
\hline Busco informações sobre concessão de benefícios. & 1 & 2,91 & 1,591 \\
\hline Busco as informações sobre contribuições previdenciárias. & 1 & 2,76 & 1,603 \\
\hline Busco as informações sobre prestação de contas do IPREVI. & 1 & 2,60 & 1,599 \\
\hline Sinto que sou capaz de compreender as informações disponíveis sobre Previdência (site, folhetos e etc). & 5 & 3,99 & 1,394 \\
\hline $\begin{array}{c}\text { Sinto que sou capaz de formar opinião própria a partir das informações disponibilizadas pelo IPREVI } \\
\text { sobre Previdência. }\end{array}$ & 5 & 3,96 & 1,421 \\
\hline Acompanho com frequência as informações divulgadas sobre Previdência. & 1 & 2,37 & 1,525 \\
\hline Busco informações sobre Previdência por meio da internet. & 1 & 2,08 & 1,574 \\
\hline Busco informações sobre Previdência por meio de impressos. & 1 & 2,39 & 1,591 \\
\hline Busco informações sobre Previdência por meio de conversas informais. & 5 & 3,24 & 1,610 \\
\hline Busco informações sobre Previdência em contato com órgãos da Prefeitura. & 1 & 2,43 & 1,622 \\
\hline Considero relevante participar de uma capacitação a respeito de temas ligados à Previdência. & 5 & 4,52 & 1,094 \\
\hline
\end{tabular}

Nota. Fonte: Resultados da pesquisa.

Quanto à compreensão sobre o que é previdência, importante considerar nesse aspecto uma variabilidade elevada, indicando valores extremos na amostra. A resposta mais frequente (4) indica que os segurados consideram compreender o que é previdência. Logo, o padrão de resposta sugere heterogeneidade para essa percepção.

Essas questões indicam o nível de educação previdenciária relacionada não apenas à gestão da previdência dos servidores, mas também às garantias e benefícios, já que ainda predomina diferenças entre o RPPS e Regime Geral de Previdência Social (RGPS). E este, pela uniformidade em âmbito nacional, tem suas regras de fruição dos benefícios, de custeio e de gestão amplamente divulgadas, se comparado aos RPPS, sobretudo os municipais. É por isso que, além do segurado entender que a proteção previdenciária é um direito de caráter contributivo, ou seja, não custeado apenas pelo Estado, como os direitos de assistência social, é necessário também diferenciar as regras que Ihes são aplicáveis para fruição desse direito. Como consequência, esse conhecimento é um pressuposto para que o segurado exerça a fiscalização da gestão previdenciária e indica, portanto, sua capacidade para produzir accountability.

Os dados indicaram ainda que os segurados consideram-se interessados nas informações sobre IPREVI e acreditam na importância de uma capacitação sobre temas ligados à previdência (médias acima de 4). Todavia, quando questionados se buscam informações sobre benefícios previdenciários, contribuições previdenciárias ou prestação de contas do IPREVI, os resultados das médias apontaram valores equivalentes ao discordo parcialmente $(2,9 ; 2,76$ e 2,60, respectivamente), o que sugere uma contradição entre o que eles percebem e o que de fato realizam.

Observou-se também que entre os meios de obtenção das informações sobre previdência, a conversa informal com os colegas e familiares foi a resposta de maior frequência entre os entrevistados. Esse fato corrobora com a importância de uma orientação previdenciária adequada aos segurados para o desenvolvimento da sua capacidade de produzir accountability.

Portanto, os resultados sugerem que embora o segurado considere compreender a previdência e a finalidade do IPREVI como unidade gestora, demonstrou pouco interesse nas informações sobre previdência. Isso foi evidenciado pelas respostas sobre as práticas de acompanhamento das informações, o que representa um fator negativo na capacidade desses segurados para produzirem accountability.

\section{B. Percepção Formal sobre Informação Transparente}

Ao serem questionados sobre o acesso ao site do IPREVI, apenas $13,3 \%$ dos segurados disseram que o conhecem. Como decorrência dessa situação, as respostas sobre as ferramentas e conteúdo do site apresentaram $88,9 \%$ de dados ausentes. Optouse pela manutenção desses dados ausentes para preservar a validade das descobertas dessa pesquisa, pois representa a impossibilidade dos segurados que não tiveram acesso ao site de indicar o que nele contém.

Quanto aos resultados das questões sobre o referido site, observou-se uma ligeira distorção na percepção daqueles que tiveram acesso a ele. Isso porque ao realizar um contraste com a realidade verificada por meio do INA, constatou-se que: esse site 
contém ferramenta de pesquisa, em alguns aspectos mantém atualizadas as informações, indica os meios para que o interessado mantenha contato com o IPREVI. Todavia, permite apenas a gravação dos documentos em um formato (PDF) e não se identificou medidas necessárias para garantir a acessibilidade de conteúdo para pessoas com deficiência.

Desse modo, embora o IPREVI tenha site próprio, a maioria do público alvo não tem acesso. Os motivos dessa realidade podem ser variados, mas não foram objeto de análise no estudo proposto, embora tenham sido percebidos durante a realização das entrevistas.

Partindo do pressuposto que algumas informações podem ser veiculadas em outros sítios eletrônicos, por meio dos quais o segurado tenha acesso, questionou-se sobre a divulgação na internet dos principais conteúdos exigidos pela legislação. Como resultado da frequência das respostas, a maioria dos entrevistados não tem acesso às informações que devem ser obrigatoriamente publicadas na internet, como: atribuições do IPREVI, horário de atendimento ao público e respostas a perguntas mais frequentes.

$\mathrm{Na}$ análise do critério transparência ativa, questionou-se sobre o conteúdo divulgado pelo IPREVI independente do meio. As respostas também seguiram a coerência das anteriores e apresentaram maior frequência na alternativa 'não sei'. Entretanto, em algumas alternativas identificou-se maior frequência da resposta 'não' em relação às variáveis anteriores, imprimindo uma ideia de certeza sobre a ausência de divulgação dos quesitos perguntados.

Nesses aspectos, percebe-se que os segurados que responderam 'não' em alguns quesitos apresentaram uma percepção coerente sobre a informação, pois não foi identificado no panorama institucional da accountability no IPREVI: a divulgação das datas e locais das reuniões do Conselho Gestor, que são públicas (Lei 1.634/2004); os critérios explícitos adotados para garantir o equilíbrio financeiro e atuarial; notas explicativas que permitam ao segurado compreender os demonstrativos contábeis; e, as projeções atuariais do RPPS.

Pelo exposto, é possível concluir que a maioria dos segurados não tem conhecimento sobre a organização do IPREVI no que se refere à sua política de transparência e não conhece ou não tem acesso aos meios pelos quais as informações são divulgadas. Portanto, tem poucas condições de manifestar sobre a accountability nesse aspecto.

\section{Percepção Substancial sobre Informação Transparente}

No constructo percepção substancial, buscou-se analisar a satisfação do segurado e a sua percepção sobre: a qualidade das informações divulgadas e transmitidas pelo IPREVI; o grau de compreensão das informações; e, a percepção sobre o nível de acessibilidade das informações mantidas pelo IPREVI sobre os benefícios e a gestão do regime.

Nesse aspecto, o nível de satisfação dos segurados apresentou valores muito baixos, pois praticamente em todas as variáveis de satisfação a média indicou valores próximos ao grau 3 da escala Likert que equivale a 'indiferente' ou ao grau 2 correspondente à 'discordância parcial' (Tabela 4).

Tabela 4: Valores estatísticos das variáveis que compõe o constructo Percepção Substancial sobre Informação Transparente.

\begin{tabular}{|c|c|c|c|}
\hline PERCEPÇÃO SUBSTANCIAL INFORMAÇÃO & MODA & MÉDIA & $\begin{array}{l}\text { DESVIO } \\
\text { PADRÃO }\end{array}$ \\
\hline As informações divulgadas pelo IPREVI são atualizadas. & 3 & 3,02 & 1,199 \\
\hline As informações disponíveis no site do IPREVI são claras. & $5^{a}$ & $4,33^{\mathrm{a}}$ & $1,231^{\mathrm{a}}$ \\
\hline O acesso ao conteúdo das informações divulgadas no site é fácil. & $4^{a}$ & $3,33^{a}$ & $1,557^{\mathrm{a}}$ \\
\hline As informações transmitidas pelos funcionários do IPREVI são claras. & 3 & 3,16 & 1,208 \\
\hline Os informativos divulgados pelo IPREVI são claros. & 3 & 3,22 & 1,339 \\
\hline $\begin{array}{l}\text { As informações disponíveis nos relatórios e demonstrativos contábeis são claras e de fácil } \\
\text { compreensão. }\end{array}$ & 3 & 2,96 & 1,180 \\
\hline Quando tenho acesso a alguma informação sobre IPREVI ou Previdência compreendo. & 5 & 3,98 & 1,218 \\
\hline A forma como a informação é divulgada pelo IPREVI me estimula a participar. & 1 & 2,41 & 1,437 \\
\hline $\begin{array}{c}\text { Considero que o IPREVI permite ao segurado amplo acesso às informações sobre } \\
\text { previdência (benefícios, contribuições). }\end{array}$ & 1 & 2,76 & 1,516 \\
\hline $\begin{array}{c}\text { Considero que o IPREVI permite ao segurado amplo acesso às informações sobre a gestão } \\
\text { dos recursos previdenciários. }\end{array}$ & 1 & 2,51 & 1,400 \\
\hline
\end{tabular}

Nota: Fonte: Resultados da pesquisa a $86,7 \%$ Dados ausentes.

Ressalta-se que esse resultado deve ser aferido em consonância com os dos constructos anteriores, a respeito da informação transparente, perfil e percepção formal. Desse modo, verifica-se que a maioria dos segurados entrevistados, por não ter acesso às informações e aos meios em que são veiculadas, não consegue avaliar a qualidade das informações prestadas.

Assim, a única avaliação positiva a respeito da informação transparente indica que para os que conhecem o site do IPREVI, as informações divulgadas nesse meio são claras (média 4,33). Entretanto, para esse mesmo grupo de segurados, a média das respostas indica que eles não fazem uma avaliação positiva sobre a facilidade de acesso ao conteúdo do site, embora essa variável apresente o maior desvio padrão em relação às outras desse constructo.

Quanto aos demais resultados, percebeu-se uma avaliação negativa quanto ao nível de transparência ativa do IPREVI no questionamento sobre o estímulo à participação a partir da informação divulgada (média 2,41 ), em que $43,3 \%$ dos segurados afirmaram discordar totalmente, $7,8 \%$ discordar parcialmente e $24,4 \%$ disseram indiferentes.

O mesmo ocorreu nas questões em que o segurado manifestou discordar que o IPREVI permite amplo acesso às informações sobre 
benefícios e contribuições (média 2,76) e também sobre gestão dos recursos previdenciários (média 2,51).

Logo, os dados indicam um nível baixo de satisfação do segurado quanto à acessibilidade e à qualidade das informações, o que compromete a realização do elemento Informação transparente da accountability no IPREVI.

\subsubsection{Participação e envolvimento do segurado}

A Participação e Interação como elemento de accountability manifesta-se nas possibilidades de envolver os segurados na implementação e execução das políticas de proteção previdenciária, de forma a permitir o exercício do controle social na verificação de condutas responsivas do agente público.

\section{A. Perfil do segurado sobre Participação}

Os dados das variáveis desse constructo indicaram que os entrevistados consideram importante discutir questões previdenciárias no âmbito sindical, bem como estabelecer contato com o IPREVI para resolver questões sobre previdência, já que as médias das respostas foram respectivamente 4,44 e 4,71, valores próximos ao grau máximo de concordância da escala utilizada.
Por outro lado, o valor da média $(2,48)$ para a pergunta referente ao contato frequente com o IPREVI para resolver questões sobre previdência indica grau de discordância. Sendo assim, é possível inferir que mesmo o segurado considerando importante manter contato com o IPREVI, ele usualmente não o faz. Ressalta-se que durante a aplicação das entrevistas observou-se que as razões desse resultado podem ser variadas, desde a ausência de motivo para estabelecer contato com a unidade gestora, ao próprio desinteresse do segurado.

O resultado das médias obtidas, demostradas na Tabela 5 , indicou que os segurados entrevistados não compreendem as funções do Conselho Previdenciário e do Conselho Fiscal e que não possuem interesse em ser representante dos seus pares nesses órgãos colegiados. Além disso, observou-se que os segurados não buscam saber quem são os seus representantes nesses Conselhos.

Todavia, quando questionados sobre o interesse em participar de alguma reunião do Conselho Previdenciário o valor da média elevou-se $(3,63)$ indicando um valor tendente ao grau de concordância.

Tabela 5 - Valores estatísticos das variáveis que compõe o Perfil sobre Participação

\begin{tabular}{|c|c|c|c|c|}
\hline & PERFIL PARTICIPAÇÃO & MODA & MÉDIA & $\begin{array}{l}\text { DESVIO } \\
\text { PADRÃO }\end{array}$ \\
\hline \multirow[b]{2}{*}{ Compreendo } & as funções do Conselho Previdenciário. & 1 & 2,63 & 1,547 \\
\hline & o funcionamento do Conselho Previdenciário. & 1 & 2,58 & 1,499 \\
\hline \multirow{3}{*}{ Tenho interesse em } & participar de alguma reunião do Conselho Previdenciário. & 5 & 3,63 & 1,618 \\
\hline & ser representante dos seus pares no Conselho Previdenciário. & 1 & 2,17 & 1,588 \\
\hline & ser representante dos seus pares no Conselho Fiscal. & 1 & 2,03 & 1,517 \\
\hline \multirow{2}{*}{ Busco saber quem } & é o meu representante no Conselho Previdenciário. & 1 & 2,66 & 1,677 \\
\hline & é o meu representante no Conselho Fiscal. & 1 & 2,63 & 1,672 \\
\hline \multirow{2}{*}{ Sinto que } & sou capaz de participar do Conselho Previdenciário. & 5 & 3,29 & 1,581 \\
\hline & $\begin{array}{l}\text { sou capaz de ser representante dos meus pares no Conselho } \\
\text { Previdenciário. }\end{array}$ & 1 & 2,91 & 1,633 \\
\hline
\end{tabular}

Nota. Fonte: Resultados da pesquisa. Os resultados indicaram também que os segurados entrevistados consideram relevante participar das audiências públicas que discutam aspectos ligados à previdência e que se sentem capacitados para participar dessas audiências para discutir a gestão do RPPS

Em suma, os resultados para esse constructo sugeriram uma contradição no perfil dos segurados sobre vários aspectos que envolvem a participação. Isso porque eles sentem-se capazes de participar, mas, na prática, não realizam essa interação por meio dos instrumentos de participação existentes. Como os resultados indicaram também a não compreensão a respeito do funcionamento desses instrumentos, esta pode ser uma das razões pelas quais o segurado não demonstrou participar. Essa situação compromete a capacidade do segurado do IPREVI para produzir accountability.

\section{B. Percepção Formal sobre Participação e envolvimento do segurado}

O diagnóstico institucional do elemento Participação indicou que no IPREVI há Conselho Municipal de Previdência e Conselho Fiscal, ambos são órgãos colegiados que têm a composição dos seus membros formada por meio de eleições periódicas entre os servidores públicos de cargo efetivo do município de Viçosa/MG (Lei 1.634/2004).

A frequência das respostas sugere que mais de $50 \%$ dos segurados sabem que o IPREVI possui Conselho Previdenciário e $70 \%$ afirmam existir eleições para a escolha do seu representante nesse Conselho. No entanto, a maioria dos segurados não participou do processo de escolha desse representante $(55,6 \%)$, não sabe quem os representa $(68,9 \%)$ e tampouco quem são os membros que compõe esse Conselho $(84,4 \%)$.

Os segurados, em sua maioria, também afirmaram existir Conselho Fiscal no IPREVI (56,7\%) e eleições para a escolha do seu representante neste Conselho (54,4\%). Assim como quanto ao Conselho Previdenciário, a maioria não participou do processo de escolha do Conselheiro Fiscal, que representa os segurados $(66,7 \%)$, também não sabem quem os representa $(83,3 \%)$ e quem são os membros desse Conselho (86,7\%).

Outra exigência normativa que busca promover a interação dos segurados refere-se às audiências ou consultas públicas. Nesse caso, identificou-se que ocorrem audiências públicas periódicas promovidas pela Câmara Municipal de Vereadores do município de Viçosa/MG, na qual todos os órgãos e entidades da Administração Pública desse município apresentam suas contas ao público.

Entretanto, apenas $12,2 \%$ dos segurados afirmaram que o IPREVI promove audiências públicas a respeito da Previdência e gestão do RPPS. Quando questionados sobre a participação 
nessas audiências, esse percentual foi ainda menor e apenas 8,9\% afirmou ter participado.

Portanto, o resultado dessas frequências indicou que a percepção formal do segurado sobre participação e interação é deficitária, principalmente porque o segurado pouco conhece sobre os meios de interação com o IPREVI e não apresenta interesse na gestão do RPPS. Consequentemente, essa percepção compromete a qualidade e o desenvolvimento do processo de accountability.

\section{Percepção Substancial sobre Participação e envolvimento do segurado}

Observando a Tabela 6, verifica-se que, praticamente todas as médias indicaram valores entre o grau de discordância ao grau de indiferença, ou seja, nas variáveis que compõe esse constructo o nível de satisfação e percepção positiva sobre a interação e os instrumentos de participação também são baixos.

Tabela 6 -Valores estatísticos do constructo Percepção Substancial sobre Participação

\begin{tabular}{|c|c|c|c|}
\hline PERCEPÇÃO SUBSTANCIAL PARTICIPAÇÃO & MODA & MÉDIA & DESVIO PADRÃO \\
\hline $\begin{array}{l}\text { O Conselho Previdenciário do município contribui para o desenvolvimento da previdência dos } \\
\text { servidores municipais. }\end{array}$ & $3^{\mathrm{a}}$ & $3,61^{\mathrm{a}}$ & $1,255^{\mathrm{a}}$ \\
\hline Estou satisfeito com o funcionamento do Conselho Previdenciário. & $3^{a}$ & $3,24^{\mathrm{a}}$ & $1,251^{\mathrm{a}}$ \\
\hline Quando procuro o IPREVI para solucionar problemas o atendimento dado é satisfatório. & 5 & 3,78 & 1,139 \\
\hline $\begin{array}{l}\text { adequado o processo de escolha do representante dos segurados no Conselho } \\
\text { Previdenciário. }\end{array}$ & $5^{a}$ & $3,22^{\mathrm{a}}$ & $1,476^{\mathrm{a}}$ \\
\hline satisfatória a representação do meu representante no Conselho Previdenciário. & $3^{\mathrm{a}}$ & $3,29^{a}$ & $1,307^{\mathrm{a}}$ \\
\hline satisfatória a representação do segurado no Conselho Fiscal. & $3^{b}$ & $3,59^{b}$ & $1,169^{b}$ \\
\hline satisfatórias as audiências públicas realizadas sobre a gestão do RPPS. & $5^{c}$ & $4,25^{c}$ & $1,035^{c}$ \\
\hline
\end{tabular}

Notas: Fonte: Resultados da pesquisa. a 45,6 Dados ausentes. ${ }^{\text {b }} 43,3 \%$ Dados ausentes. ${ }^{c} 91,1 \%$ Dados ausentes.

Salienta-se, contudo, que no exame da percepção substancial é imprescindível a análise em conjunto com os resultados dos constructos perfil e percepção sobre a participação. Assim, a constatação de que a maioria dos segurados não conhece os meios pelos quais é possível participar da gestão do RPPS e também não realiza na prática essa interação compromete a capacidade deste para avaliar a qualidade dos instrumentos existentes. Desse modo, na quase totalidade dessas variáveis, apenas parcela dos segurados entrevistados avaliaram os quesitos desse constructo.

Assim, na percepção dos segurados que sabem que o IPREVI possui Conselho Previdenciário, ou seja, 54,4\% (Tabela 12), não é possível dizer que esse órgão contribui para o desenvolvimento da previdência dos servidores públicos municipais, já que tanto a média, quanto a moda indicaram valores que representam o grau de indiferença na escala utilizada. Nesse sentido, o mesmo percentual de entrevistados também não se sente satisfeito, nem insatisfeito com o Conselho.

Quanto à adequação do processo de escolha do representante dos segurados no Conselho Previdenciário, a média também indicou essa indiferença. Todavia, percebeu-se uma dispersão de valores maior em torno da média para essa variável e o valor da moda indicou grau máximo de concordância.

A partir desses resultados, é possível concluir que percepção substancial do segurado sobre participação e interação com o IPREVI é positiva apenas em poucos aspectos, o que reflete na avaliação do nível de accountability dessa unidade gestora em relação ao elemento Participação e Interação.

\subsubsection{Mecanismos de Controle}

A aferição do elemento Mecanismos de Controle institucionalizados foi pautada também nos constructos perfil e percepção a respeito da fiscalização do exercício da função pública no âmbito do IPREVI.

\section{A. Perfil do segurado sobre os mecanismos de controle}

Observou-se, nesse caso, a legitimidade de algumas instituições de controle na medida em que os segurados apresentaram praticamente um consenso quanto ao seu poderdever de fiscalizar, como é o caso do Ministério Público (MP), do Tribunal de Contas do Estado de Minas Gerais (TCE MG) e do Conselho Fiscal do IPREVI.

Ressalta-se que quanto ao Sindicato, embora este não tenha o poder-dever de fiscalizar o IPREVI, optou-se por inserí-lo na variável por dois motivos: primeiro, porque pode exercer o controle social e acionar os demais órgãos de controle; segundo, por ser a instituição de deliberação e representação mais próxima da realidade dos segurados entrevistados, pois são servidores em atividade.

Embora a maioria dos segurados acredite que o Conselho Fiscal do IPREVI pode fiscalizar a unidade gestora, os resultados apontaram que aqueles não compreendem as funções e o funcionamento dos órgãos de controle interno do IPREVI: Conselho Fiscal e Comitê de Investimentos.

No entanto, os segurados consideram relevantes: seu papel no acompanhamento da gestão do RPPS; a existência de fiscalização dessa atividade; os limites estabelecidos pela lei na condução do RPPS; e, a realização de auditorias no IPREVI. Todas essas variáveis, conforme expõe a Tabela 7 , apresentaram médias e valores da moda próximos ao grau máximo de concordância, além dos baixos valores do desvio padrão. 
Tabela 7- Valores estatísticos do Perfil do segurado sobre Controle

\begin{tabular}{|c|c|c|c|}
\hline PERFIL CONTROLE & MODA & MÉDIA & $\begin{array}{c}\text { DESVIO } \\
\text { PADRÃO }\end{array}$ \\
\hline as funções do Comitê de Investimentos do IPREVI. & 3 & 2,59 & 1,413 \\
\hline as funções do Conselho Fiscal. & 1 & 2,89 & 1,625 \\
\hline o funcionamento do Conselho Fiscal. & 1 & 2,59 & 1,557 \\
\hline a fiscalização da gestão do IPREVI. & 5 & 4,58 & 874 \\
\hline o papel do segurado na fiscalização (acompanhamento) do IPREVI. & 5 & 4,78 & ,576 \\
\hline a realização de auditorias no IPREVI. & 5 & 4,90 & ,337 \\
\hline a lei estabelecer limites para a gestão do RPPS. & 5 & 4,54 & ,901 \\
\hline \multirow{2}{*}{$\begin{array}{l}\text { Busco informar as autoridades quando observo alguma situação irregular no IPREVI. } \\
\text { Considero as propostas sobre previdência para definir meu voto nas eleições municipais, seja } \\
\text { para prefeito ou para vereador. }\end{array}$} & 5 & 3,23 & 1,608 \\
\hline & 5 & 3,74 & 1,503 \\
\hline
\end{tabular}
Nota. Fonte: Resultados da pesquisa.

Em suma, conclui-se que o segurado do IPREVI reconhece nos órgãos de controle externo legitimidade para fiscalizar a unidade gestora, por isso atribui a esse tipo de controle maior importância. Entretanto, quanto aos órgãos de controle interno, não compreende suas funções, o que acaba por distanciá-lo da sua capacidade para produzir accountability, refletindo também no seu distanciando perante o IPREVI, como observado nos constructos da Informação Transparente e da Participação e Envolvimento do segurado.

\section{B. Percepção Formal sobre mecanismos de controle}

No constructo percepção formal, buscou-se examinar o conhecimento do segurado sobre a existência e a finalidade dos instrumentos de controle dos quais ele pode ter acesso imediato ou mais próximo (ouvidoria, Conselho Fiscal, Comitê de Investimentos, auditorias).

Os resultados da frequência das respostas indicaram que a maioria dos segurados não sabe se o IPREVI possui Comitê de Investimentos e ouvidoria. Entretanto, no exame do panorama institucional do IPREVI verificou-se que existe este órgão (Lei 1.634/2004) e há no site do IPREVI um link direcionado à ouvidoria.

Tabela 8 - Frequência da Percepção Formal sobre Controle

\begin{tabular}{|c|c|c|c|}
\hline $\begin{array}{l}\text { PERCEPÇÃO FORMAL } \\
\text { CONTROLE }\end{array}$ & NÃO SEI & NÃO & SIM \\
\hline \multirow{2}{*}{$\begin{array}{l}\text { O IPREVI possui Comitê de } \\
\text { Investimentos (decisões sobre a } \\
\text { política de investimentos). } \\
\text { O IPREVI tem ouvidoria. }\end{array}$} & $80,0 \%$ & $1,1 \%$ & $18,9 \%$ \\
\hline & $77,8 \%$ & $12,2 \%$ & $10,0 \%$ \\
\hline Já utilizou a ouvidoria do IPREVI. & $3,3 \%$ & $95,6 \%$ & $1,1 \%$ \\
\hline $\begin{array}{l}\text { Por meio da ouvidoria o segurado } \\
\text { poderá informar alguma } \\
\text { irregularidade na condução do } \\
\text { RPPS. }\end{array}$ & $58,9 \%$ & $6,7 \%$ & $34,4 \%$ \\
\hline $\begin{array}{l}\text { O Conselho Fiscal do IPREVI } \\
\text { fiscaliza a regularidade das contas } \\
\text { da unidade gestora (IPREVI). } \\
\text { O Comitê de Investimento auxilia }\end{array}$ & $55,6 \%$ & $6,7 \%$ & $37,8 \%$ \\
\hline $\begin{array}{l}\text { na definição da política de } \\
\text { investimento do RPPS. }\end{array}$ & $81,1 \%$ & $1,1 \%$ & $17,8 \%$ \\
\hline $\begin{array}{l}\text { A audiência pública de prestação } \\
\text { de contas do IPREVI realizada na } \\
\text { Câmara dos Vereadores permite a } \\
\text { fiscalização do IPREVI. }\end{array}$ & $83,3 \%$ & $0,0 \%$ & $16,7 \%$ \\
\hline $\begin{array}{l}\text { O IPREVI se submete a auditorias } \\
\text { (internas e externas). }\end{array}$ & $56,7 \%$ & $6,7 \%$ & $36,7 \%$ \\
\hline
\end{tabular}

Destarte os resultados apresentados sobre a percepção formal do segurado, quanto ao controle, indicam que o segurado do IPREVI tem pouco conhecimento sobre os mecanismos e órgãos de controle mais próximos da sua realidade. Essa conclusão afeta a realização da accountability, principalmente na perspectiva do segurado.

\section{Percepção Substancial sobre mecanismos de controle}

No constructo Percepção Substancial sobre controle, averiguou-se a compreensão e o grau de satisfação dos segurados com os instrumentos de controle e com a fiscalização exercida no IPREVI.

Percebe-se que menos de $10 \%$ dos segurados tiveram condições para avaliar as questões sobre a ouvidoria do IPREVI. Assim, esse pequeno grupo de segurados não consideram o acesso à ouvidoria satisfatório, nem insatisfatório. A maioria também não sabem concordar ou discordar se por meio desse instrumento as investigações ou fiscalizações são realizadas. Além disso, são indiferentes também quanto à avaliação a respeito do tempo de resposta das reclamações e da maneira como essas respostas são realizadas. Esses resultados sugerem que o segurado apenas sabe da existência desse instrumento.

No que tange ao Conselho Fiscal, os dados mantiveram o mesmo parâmetro das ouvidorias (Tabela 9) e os segurados que avaliaram a atuação, o funcionamento e a contribuição desse órgão para a gestão do RPPS também não apresentaram concordância ou discordância a respeito desses pontos.

Tabela 9 - Frequência do constructo Percepção Substancial sobre Controle

\begin{tabular}{|c|c|c|c|}
\hline $\begin{array}{l}\text { PERCEPÇÃO SUBSTANCIAL } \\
\text { CONTROLE }\end{array}$ & MODA & MÉDIA & $\begin{array}{l}\text { DESVIO } \\
\text { PADRÃO }\end{array}$ \\
\hline $\begin{array}{l}\text { Considero satisfatória a atuação do } \\
\text { Conselho Fiscal do IPREVI. }\end{array}$ & $3^{a}$ & $3,51^{\mathrm{a}}$ & $1,065^{\mathrm{a}}$ \\
\hline $\begin{array}{l}\text { O Conselho Fiscal contribui para a } \\
\text { gestão adequada dos recursos } \\
\text { previdenciários. }\end{array}$ & $3^{a}$ & $3,65^{a}$ & $1,055^{\mathrm{a}}$ \\
\hline Estou satisfeito com o funcionamento & $3^{\mathrm{a}}$ & $3,55^{a}$ & $1,137^{a}$ \\
\hline
\end{tabular}

Nota. Fonte: Resultados da pesquisa. ${ }^{\text {a }} 43,3 \%$ dados ausentes

Por outro lado, embora na percepção formal sobre controle os resultados tenham indicado que para os segurados o Comitê de Investimentos não promove acessibilidade às informações relativas aos processos de investimento dos recursos do RPPS, os $17,8 \%$ dos segurados entrevistados fizeram uma avaliação positiva a respeito desse órgão. Isso porque, na percepção desse grupo, o órgão contribui para a gestão adequada dos recursos previdenciários e estão satisfeitos com o seu funcionamento.

Os resultados demonstram que as médias mais altas para as variáveis que compõe esse constructo referem-se aos instrumentos de controle externo do IPREVI. Mas, o valor da média $(2,91)$ indicou 
que os segurados não consideram satisfatória a fiscalização exercida pelos órgãos de controle (Tabela 10).

\begin{tabular}{|c|c|c|c|}
\hline $\begin{array}{l}\text { PERCEPÇÃO SUBSTANCIAL } \\
\text { CONTROLE }\end{array}$ & MODA & MÉDIA & $\begin{array}{l}\text { DESVIO } \\
\text { PADRÃO }\end{array}$ \\
\hline $\begin{array}{c}\text { Considero satisfatória a } \\
\text { fiscalização exercida pelos órgãos } \\
\text { de controle. }\end{array}$ & 3 & 2,91 & 1,278 \\
\hline $\begin{array}{l}\text { A lei favorece o controle das } \\
\text { atividades da unidade gestora. }\end{array}$ & 3 & 3,40 & 1,188 \\
\hline $\begin{array}{l}\text { Considero satisfatória a audiência } \\
\text { pública de prestação de contas do } \\
\text { IPREVI realizada na Câmara dos } \\
\text { Vereadores. }\end{array}$ & 5 & $4,03^{a}$ & $1,104^{\mathrm{a}}$ \\
\hline $\begin{array}{c}\text { As auditorias realizadas no IPREVI } \\
\text { contribuem para a qualidade da } \\
\text { gestão do RPPS. }\end{array}$ & 5 & $4,36^{b}$ & $1,186^{b}$ \\
\hline
\end{tabular}

Nota. Fonte: Resultados da pesquisa. ${ }^{a} 63,3 \%$ dados ausentes. ${ }^{b}$

$72,2 \%$ dados ausentes

Em síntese, os resultados sugerem que a percepção substancial dos segurados sobre controle é positiva em poucos aspectos e que, no geral, eles não estão satisfeitos com os órgãos e instrumentos de controle interno do IPREVI.

\subsubsection{Previsão de sanções}

O elemento Previsão de Sanções foi analisado e mensurado a partir do conhecimento e da avaliação do segurado sobre as possíveis consequências jurídicas das condutas praticadas no exercício da gestão previdenciária.

\section{A. Perfil do segurado sobre sanções previstas}

A análise da capacidade do segurado para produzir accountability, nesse aspecto, deu-se através do conhecimento sobre as autoridades com poder de punir e da importância atribuída às diferentes naturezas de sanções punitivas.

Observou-se pela frequência das respostas que os segurados acreditam que todos os órgãos e entidades indicados nas variáveis tem poder para punir o IPREVI. Embora nem todos tenham de fato o poder de aplicar sanções jurídicas (Sindicato, Conselho Fiscal), os dados sugerem que o segurado atrela o exercício da fiscalização com a sanção correspondente. Porém, para a capacidade de produzir accountability é relevante que ele saiba da possibilidade de alguns desses órgãos aplicarem as sanções.

Quanto à importância atribuída à previsão de sanções punitivas, os dados indicam que os segurados concordam com a previsão de sanções de todas as naturezas como consequência para atos de irregularidades na gestão do RPPS e que deixariam de votar no candidato que foi punido por alguma questão atrelada à previdência.

Portanto, os resultados indicam que o perfil do segurado quanto ao elemento sanção o capacita para produzir accountability, pois os segurados conhecem os órgãos com poder de aplicar sanções e consideram importante a previsão dessas como meio de responsabilização pelas condutas praticadas.

\section{B. Percepção Formal sobre sanções previstas}

A percepção formal sobre sanção indicou o conhecimento do segurado sobre possíveis punições no âmbito da gestão dos recursos previdenciários. Identificou-se, nessa análise, que os segurados, que também são servidores públicos, sabem que os servidores encarregados de encaminhar relatórios aos órgãos e entidades de controle podem ser punidos administrativamente.

No mesmo sentido, quase $90 \%$ dos segurados afirmaram que todos os envolvidos na gestão dos recursos previdenciários podem ser responsabilizados por meio das sanções punitivas administrativas, civis e penais.

Constata-se, nessa análise, que o segurado apresenta uma percepção formal adequada a respeito das possíveis sanções decorrentes da prática irregular da gestão no âmbito da Administração Pública. Desse modo, esse aspecto propicia o desenvolvimento da accountability no IPREVI.

\section{Percepção Substancial sobre sanções previstas}

O constructo percepção substancial buscou examinar a percepção e o grau de satisfação do segurado sobre as possibilidades de punições existentes, bem como a sua aplicação, conforme resultados apresentados na Tabela 11.

Tabela 11 -Frequência do constructo Percepção Substancial sobre sanções

\begin{tabular}{|c|c|c|c|}
\hline $\begin{array}{l}\text { PERCEPÇÃO SUBSTANCIAL } \\
\text { SANÇÃO }\end{array}$ & MODA & MÉDIA & $\begin{array}{l}\text { DESVIO } \\
\text { PADRÃO }\end{array}$ \\
\hline $\begin{array}{l}\text { Considero satisfatória a } \\
\text { possibilidade de punições } \\
\text { existentes atualmente quando } \\
\text { constatado irregularidade na } \\
\text { gestão do RPPS. }\end{array}$ & 5 & 3,47 & 1,455 \\
\hline $\begin{array}{c}\text { Considero que são aplicadas as } \\
\text { devidas punições aos infratores } \\
\text { quando constatada irregularidade } \\
\text { na gestão do RPPS. }\end{array}$ & 3 & 2,81 & 1,397 \\
\hline
\end{tabular}
segurado sobre sanção sugere uma relativa satisfação com as possibilidades de punições existentes, porém uma insatisfação em relação à aplicabilidade dessas consequências. Essa avaliação interfere no processo de accountability sob vários aspectos, principalmente no elemento participação e, por consequência, no exercício do controle social.

\subsection{Accountability vertical, social e horizontal no IPREVI}

O cenário da accountability exposto nos resultados apresentados permitiu observá-la como o processo no qual a avaliação da gestão e a responsabilização decorrente dos atos praticados no exercício dessa atividade ocorrem por meio das relações entre o IPREVI e o segurado, bem como, entre o IPREVI e os órgãos de controle. Assim, foi possível examinar a accountability a partir das suas usuais classificações: vertical, social e horizontal.

Ao apreciar as relações entre o IPREVI e o segurado duas situações devem ser destacadas: primeiro, que existe uma relação de verticalidade inerente à própria função pública exercida pela unidade gestora enquanto entidade da Administração Pública indireta; segundo, a avaliação e a responsabilização que ocorrem nessa relação vertical podem ser realizadas por diversos meios, mas nesse estudo foram considerados apenas os institucionalizados formalmente. 
Desse modo, considerando a classificação da accountability vertical como sendo aquela que se realiza por meio das eleições (O'Donnell, 1998), verificou-se que no IPREVI esta se materializa no processo de escolha dos representantes dos segurados nos órgãos colegiados: Conselho Municipal de Previdência e Conselho Fiscal.

No entanto, os resultados a respeito da análise desses espaços de representação indicaram que a maioria dos segurados não participou do processo de escolha dos seus representantes nesses Conselhos e não sabem, inclusive, quem os representa.

Em outra perspectiva, observou-se que aproximadamente 60\% dos segurados consideram as propostas sobre previdência para definir o seu voto nas eleições municipais.

Embora aparentemente o poder político extrapole a relação unidade gestora - segurado, os Poderes Legislativo e Executivo municipais exercem influência na gestão do IPREVI. Isso porque, a representação de ambos nesses órgãos ocorre por indicação e a composição da Diretoria da unidade gestora é formada por escolha do Prefeito a partir de uma lista tríplice encaminhada pelo Conselho Municipal de Previdência (Lei 1.634/2004).

Assim sendo, esses aspectos devem ser considerados para apresentação adequada da conjuntura da accountability vertical no IPREVI e indicam que existem mecanismos para viabilizá-la, embora na prática não seja plenamente realizada.

No que se refere à accountability social, societal ou vertical não eleitoral (Peruzzotti \& Smulovitz, 2000; Robl Filho, 2013), esta é compreendida como a que é "exercida diretamente pela sociedade sobre os agentes públicos, eleitos, nomeados ou permanentes" (Rocha, 2011, p.87). Dessa forma, é mais ampla que a vertical porque não se esgota nas eleições.

Nesse aspecto, o panorama institucional do IPREVI sugere a presença de vários mecanismos de accountability social, como: a existência do Conselho Municipal de Previdência com a representação paritária dos segurados ativos e inativos; o Conselho Fiscal; a indicação de um sistema de ouvidoria no site do instituto; a divulgação de alguns aspectos da gestão em site próprio; e, a realização periódica de audiências públicas de prestação de contas do IPREVI realizada na Câmara dos Vereadores.

Não obstante, em relação a todos esses instrumentos que permitem o exercício do controle social sobre a gestão previdenciária do RPPS, os resultados do perfil e da percepção dos segurados demonstraram que a accountability social não é vivenciada a partir do potencial apresentado institucionalmente. Essa circunstância não seria problemática se fossem observadas práticas de interação e participação efetivas dos segurados no controle social da gestão previdenciária, mas como nesse aspecto a previsão legal já é limitada, entende-se que esse subaproveitamento do aparato institucional prejudica a realização da accountability.

Importante registrar que esse estudo não examinou a atuação das entidades representativas de classes quanto à defesa dos interesses previdenciários dos seus associados, mas foi observado que os segurados em sua maioria conferem legitimidade ao Sindicato para realizar esse papel fiscalizador junto ao IPREVI.
Percebeu-se também, que o segurado na prática não exerce o controle social da gestão previdenciária. Na verdade, ele tende a delegar essa função fiscalizadora de forma exclusiva aos órgãos e às entidades, sobretudo, aos estatais.

Quanto à accountability horizontal, ela ocorre entre os órgãos e agentes do Estado na concretização da fiscalização entre os poderes, na verificação das condutas conforme determinam as leis (O’Donnell, 1998; Rocha, 2011). Por isso, para identificá-la observou-se a relação entre o IPREVI e os órgãos e entidades estatais de controle.

Nessa seara, os resultados indicaram que as atividades exercidas no âmbito das unidades gestoras submetem-se a sistemas múltiplos e rígidos de controle externo e interno. Entendese, inclusive, que esse é o elemento mais desenvolvido do processo de accountability desencadeado no IPREVI.

Todavia, cabe ressaltar que a percepção dos segurados sobre esse aspecto sugeriu uma crise de legitimidade dos controles internos realizados no instituto. Ademais, como não foram identificadas sanções punitivas atreladas à gestão do RPPS, o que faz voltar o questionamento anterior à tona: o controle tem sido ou não eficaz? Como já mencionado, a definição de uma conclusão coerente com a realidade do IPREVI ensejaria análises bem pontuais que fogem ao escopo deste trabalho, mas pode servir de subsídio para pesquisas futuras.

No momento, importa reconhecer que há no IPREVI vários mecanismos institucionalizados de accountability vertical, social e horizontal, embora não sejam utilizados em todo o seu potencial.

\section{Considerações Finais}

Este estudo permitiu visualizar o cenário da accountability no Instituto de Previdência dos Servidores Públicos do Município de Viçosa/MG - IPREVI. Dessa forma, observou-se uma contradição entre o aparato institucional dos elementos que compõe a accountability na realidade dessa unidade gestora com a sua realização em relação ao perfil e às percepções do segurado. Percebeu-se que o segurado não apresentou capacidade para produzir accountability, sobretudo, pela falta de informação e de interesse em atuar como um agente de accountability.

Por outro lado, embora exista no IPREVI uma tendência incipiente ao desenvolvimento de uma cultura organizacional pautada na transparência ativa, as informações divulgadas pelo instituto se revestem de estrutura muito técnica que dificulta o estabelecimento de um canal de comunicação com o segurado e gera entraves no incentivo de sua participação.

Ademais, as constatações a respeito dos controles e sanções confirmaram essa realidade contraposta entre aspectos formais e substanciais do processo de avaliação e responsabilização no âmbito da gestão previdenciária.

Além dessas circunstâncias pontuais, os resultados dessa investigação permitiram identificar os mecanismos institucionalizados de accountability vertical, social e horizontal no IPREVI. E, também sob esse ângulo de análise, o contraste entre a realidade institucional e a vivência da accountability se destacou como característica marcante das conclusões desse estudo. 
Portanto, e em síntese, nos aspectos formais o IPREVI possui aparato para realizar todos os elementos da accountability de modo que esta possa manifestar-se através das relações vertical, social e horizontal. Contudo, na prática não foi possível identificar a concretização dessas circunstâncias na mesma intensidade em que existem institucionalmente.

Nesse sentido, além dos resultados indicarem que a informação transparente é o elemento mais precário da accountability no IPREVI, entende-se que esse elemento deve ser a ênfase de qualquer processo consolidado de avaliação e responsabilização, cuja finalidade seja o controle em sentido amplo. Isso porque é ao mesmo tempo pressuposto desse processo e a condição mínima para que os demais elementos se manifestem.

Desse modo, foi possível concluir que o processo de avaliação da gestão da previdência no âmbito do IPREVI e a decorrente responsabilização desse processo carecem, sobretudo e respectivamente de: informação transparente, participação e envolvimento dos segurados.

\section{Referências}

Bruni, Adriano Leal. (2009). SPSS aplicado à pesquisa acadêmica. São Paulo: Atlas.

Constituição da República Federativa do Brasil 1988. (2014) Recuperado de http://www.planalto.gov.br/ccivil_03/constituicao/constituicaocompilado.htm.

Hair, F.J., Black, W. C., Babin, B., Anderson, R. E. \& Tathan, R. L.(2009) Análise multivariada de dados (6 $6^{\mathrm{a}}$ ed.). Porto Alegre: Bookman.

Lei 9.717, de 27 de novembro de 1998 (1998). Dispõe sobre regras gerais para a organização e o funcionamento dos regimes próprios de previdência social dos servidores públicos da União, dos Estados, do Distrito Federal e dos Municípios, dos militares dos 38 Estados e do Distrito Federal e dá outras providências. Recuperado

http://www.planalto.gov.br/ccivil_03/leis/L9717.htm.

Lei Complementar 101, de 04 de maio de 2000 (2000). Estabelece normas de finanças públicas voltadas para a responsabilidade na gestão fiscal e dá outras providências. Recuperado de outras providências.
http://www.planalto.gov.br/ccivil_03/leis/lcp/lcp101.htm.

Lei 12.527, de 18 de novembro de 2011 (2011).Regula o acesso a informações previsto no inciso XXXIII do art. 5o, no inciso II do § 3ㅇ do art. 37 e no $\S 2$ do art. 216 da Constituição Federal; altera a Lei no 8.112 , de 11 de dezembro de 1990; revoga a Lei no 11.111 , de 5 de maio de 2005, e dispositivos da Lei no 8.159, de 8 de janeiro de 1991; e dá outras providências. Recuperado de http://www.planalto.gov.br/ccivil_03/_ato20112014/2011/lei/l12527.htm.

Consolidação da Legislação sobre Regimes Próprios de Previdência (2014). Ministério da Previdência Social. Atualizada até setembro de 2014.
Recuperado

http://www.previdencia.gov.br/wpcontent/uploads/2014/09/CONSOLIDA\%C3 $\% 87 \%$ C3\%83O-LEGISLA\%C3\%87\%C3\%83O-RPPS-atualizadaat\%C3\%A9-22-setembro-0141.zip.

Lei Complementar municipal 1.511, de 19 de novembro de 2002 (2002). Dispõe sobre o Regime Próprio de Previdência Social dos servidores do Município de Viçosa, Minas Gerais, cria a entidade de previdência e dá outras providências. Recuperado

http://www.iprevivicosa.mg.gov.br/site/legislacao.html .

Lei 1.634, de 23 de dezembro de 2004 (2004). Dispõe sobre o Regime Próprio de Previdência Social dos Servidores do Município de Viçosa, Minas Gerais, dá nova redação à Lei Complementar no 1.511/2002 de 19 de novembro de 2002 , acerca da organização, dos benefícios previdenciários, das regras de transição e do respectivo regime de custeio. Recuperado dehttp://www.iprevivicosa.mg.gov.br/site/legislacao.html.

Decreto do Executivo 4.572, de 26 de outubro de 2012 (2012). Cria o Comitê de Investimentos do Instituto Municipal de Previdência dos Servidores do Município de Viçosa/MG e dá outras providências. Recuperado dehttp://www.iprevivicosa.mg.gov.br/site/comite-de-investimento.html.

Levin, Jack, Fox, James Alan \& Ford, David R. (2012). Estatística para ciências humanas (11 ed., Jorge Ritter, trad., Fernanda Bonafini, Revisão técnica). São Paulo: Pearson Education do Brasil.

Martins, F. J. O. (2015). Accountability nas unidades gestoras do regime próprio de previdência dos servidores públicos municipais: Um estudo de caso no IPREVI - Viçosa/MG (Dissertação de Mestrado). Universidade Federal de Viçosa, Viçosa,-MG, Brasil.

O'Donnell, Guillermo (1998). Accountability horizontal e novas poliarquias. Lua Nova [online], n. 44, 27-54. ISSN: 0102-6445.

Peruzzotti, Enrique \& Smulovitz, Catalina (2000). Societal and horizontal controls: two cases of a fruitful relationship. Institutions, Accountability and Democratic Governance in Latin America. The Helen Kellogg Institute for International Studies University of Notre Dame. Recuperado dehttp://kellogg.nd.edu/faculty/research/pdfs/Smulovit.pdf.

Robl Filho, Ilton Norberto (2013). Conselho Nacional de Justiça: estado democrático de direito e accountability. São Paulo: Saraiva.

Rocha, Arlindo Carvalho (2011). Accountability na administração pública: modelos teóricos e abordagens. Contabilidade, Gestão e Governança, v. 14, n. 2, 82-97. ISSN: 1984-3925

Schedler, A (1999). Conceptualizing accountability. In: Schedler, A., Diamond, L. \& Plattner, M. (Ed.). Self-restraining state: power and accountability in new democracies. Boulder: Lynne Rienner Publishers. 